\title{
The Integration of Post Theory and Philosophy of Event and Its Progressive Significance
}

\author{
Liu Yang \\ Department of Chinese Language and Literature, East China Normal University, Shanghai, China \\ Email address: \\ liutaiyang2001@163.com \\ To cite this article: \\ Liu Yang. The Integration of Post Theory and Philosophy of Event and Its Progressive Significance. International Journal of Literature and \\ Arts. Vol. 9, No. 4, 2021, pp. 207-211. doi: 10.11648/j.ijla.20210904.20
}

Received: August 8, 2021; Accepted: August 21, 2021; Published: August 31, 2021

\begin{abstract}
So far, there are three ideas in the study of post theory. These three existing ideas are enlightening to a certain extent, but the common shortcomings are also obvious. They all put the vision of the post theory in the Anglo-American scope, that is, they directly give the Anglo-American position to the theory, but do not aim at the European continent from the internal academic road, which is the center of the theoretical culture. This does not really prove where the theory needs to be improved. The intention of this paper is to overcome this existing limitation and try to put forward a new way of thinking, that is, the philosophy of event is used to connect and activate the post theory. In Europe, the philosophy of event is mainly manifested as a rebellion against the mainstream linguistic theory represented by Saussure. Therefore, when the Anglo-American scholars in the same period began to pay attention to "after theory", because theory is based on the mainstream linguistic theory, post theory which is mainly popular in the Anglo-American academic circles naturally introduces the philosophy of event as a further promotion. This also makes the post theoretical research go beyond the Anglo-American paradigm which is slowly falling into a certain bottleneck, and get involved in the European dynamics, obtaining the internal intermediary and new growing point. This constitutes a new train of thought of the research of post theory.
\end{abstract}

Keywords: Post Theory, Philosophy of Event, Integration

\section{Introduction}

The development of literary theory can be described as the three stages of literary theory (represented by the Literary Theory co-authored by Wellek and Warren), theory and post theory. Eagleton's book "After Theory", it typically provides the ideological background of post theoretical research. "The introduction to Contemporary Literary Theory", co-authored by Raman Seldon and other three British scholars, formally reveals the concept of "post theory" in the conclusion [1]. It can be seen that to grasp the nature of the post theory, we need to start with the general nature of the theory.

Theory is always presented as an event when it occurs, because it is a reaction to observation and contemplation of new objects. Slavoj Žižek, the representative of contemporary philosophy of event, puts forward three theoretical nodes, Plato, Descartes and Hegel, and thinks that they are "actually facing three philosophical events, in which, something new that has not been universally accepted invades this field in a traumatic way", and "the event constitutes the focus of their respective thoughts" [2]. The nature of the event at the starting point of the theory is equivalent to what Thomas Kuhn called the paradigm revolution. Just as paradigm is different from theory in Kuhn's view, the latter, as a "conventional science", plays down "anomalies and crises" and their "relatively sudden and unstructured events"[3], and calls for a new paradigm. We are equally interested in: since when did theory lose event?

This problem is particularly urgent in the recent trend of literary theory. According to Jonathan Caller's summary, the theory resists the self-evident nature of common sense and carries out disenchantment (decoding). This makes it necessary to start with something that feels different-events. But the evolution of the theory shows that it is gradually becoming something that it originally regarded as the object of criticism, that is, as opposed to event. Like the representative concern of Timothy Clark, a professor at Durham University in the UK, "assumptions that critics may well attack in texts they are studying still actively determine the culture of intellectual production for critical work (such as that 
surrounding this very book)."[4] This situation leads to the "violently formulaic reductions" of the theoretical movement [4], which makes it lose its keen perception of events and become numb and repeated. It is largely because of this that the proposition of "after theory" has been put on the current academic agenda.

How to try to get out of this situation effectively? In my opinion, with the help of philosophy of event, a new solution can be obtained. In fact, In fact, Clark discusses the most important nature of the event-"The Poetics of Singularity", which is preceded by a preface written by the American scholar Martin McQuillan, and McQuillan is one of the editors of "Post Theory: a New Direction of Cultural Criticism". This makes us feel that there is a possibility of natural connection between event and post theory.

\section{The Deficiency of the Existing Train of Thought of Post Theory}

So far, there are three ideas in the study of post theory. (1) Eagleton published "After Theory" in 2003, combing and summarizing the pros and cons of the theory, but does not think that the theory should be ended, because the specific perspective provided by the theory is still the only way for literature to obtain effective understanding. Eagleton, who is an elite theorist, does not show the slightest intention of abandoning theory. On the contrary, in declarations such as "A life without theory, there is no life without reflection", he not only continues to talk about objectivity and truth. And at the end of the third chapter of the book comes to the conclusion of the post theoretical construction, that is, "understand the meta-narrative in which it is trapped" [5]. In other words, "after theory", in his view, means bringing the theory back to meta-narrative. (2) Anti-theory. Since the theory has exposed many shortcomings as a meta-narrative, resisting its gross intervention in specific literary and artistic phenomena has become a post theoretical train of thought that some scholars are willing to adopt. In addition to Richard Rorty and Stanley Fish mentioned by Eagleton, the voices receiving attention include at least Susan Sontag's "Against Interpretation" and other voices. (3) Recently, there has been a new change in the study of humanities around the world. That is, advocating that "literariness" gradually begin to infiltrate and dominate the writing of theories. Jonathan Cutler's book Literature in Theory, published in 2007, is representative.

The above three ideas are enlightening to a certain extent, but the common shortcomings are also obvious. That is, they all put the vision of the post theory in the Anglo-American scope, directly entrusting the Anglo-American position to the theory, but not aiming at the European continent, the important scope of the theoretical culture, from the internal academic road, so as to prove where the theory needs to be improved. This not only lacks the necessary depth in the analysis as a whole, but also appears to be more preconceived and simplified in the discussion of many issues, which is not convincing enough.
The reason for the prosperity of the theory comes from the direct promotion of language. After Saussure proved that language is the distinction of symbols, Foucault and other thinkers further found that the distinction of symbols constructs the distinction of reality. Along with this, they carried out exquisite disenchantment of the ubiquitous discourse power, and formed a theoretical movement with interdisciplinary issues such as ideology, gender, ethnicity and identity politics as key words. With the full development of the theoretical movement, the self-evident paradigm of believing in things first and then naming and conveying words has been destroyed. This shows that if we want to really promote the reflection of the theory and the resulting post theoretical thinking, we must closely return to the crux of the "theory"-the mainstream linguistic theory to find a breakthrough.

On the basis of the existing ideas, this paper intends to find the above breakthrough and put forward a new post theoretical idea, that is, to integrate the post theory with the contemporary emerging philosophy of event and use event to activate the post theory.

\section{The Heterogeneous Tension Between the Philosophy of Event and the Mainstream of Linguistic Theory}

We live in a new era with multiple events, and "event" have naturally become the theme of contemporary international humanities. Please refer to my recently published book [6]. The book points out that the idea of event has become a very influential theme of humanities today. After Nietzsche, Heidegger and Bakhtin, France's Jacques Lacan, Emmanuel Levinas, Maurice Blanchot, Paul Ricoeur, Jean-Francois Lyotard, Gilles Deleuze, Michel Foucault, Jacques Derrida, Paul Virilio, Alain Badiou, Jacques Rancière, Jean-Luc Nancy, Giorgio Agamben, Jean-Luc Marion, Bernard Stiegler and Claude Romano, Slovenia's Slavoj Žižek, Britain and the United States's Willard Orman Quine, Donald Davidson, Terry Eagleton, Derek Attridge and Michael Sayeau, Canada's Brian Massumi, Japan's Komori Yoichi and Yoshio Kobayashi and Israel's Ilai Rowner, all these theorists with different academic backgrounds discussed the event enthusiastically and deeply, which made the whole pedigree of the event show polyphonic characteristics, that is, on the three levels of consciousness, history and language. To varying degrees, it permeates contemporary thoughts such as psychoanalysis, phenomenology, ontology, hermeneutics, process philosophy, philosophy of technology, semiotics and discourse politics and its life form, post-structuralism, deconstruction and analytical philosophy. and continue to form a controversial relationship between each other.

In the 2020 English translation of two recent international books, "Branches: A Philosophy of Time, Event and Advent", and "Thinking the Event", the authors Michel Serres and François Raffoul pointed out from a strategically advantageous position: "The universality and uniqueness of 
events actually pervade every measure of power from the great to the smallest." [7] "The category of events has become the main concern of contemporary mainland thought." [8] The original intention of the rise of contemporary philosophy of event is to resist the disguised presupposition of the safety and stability of the structure by the mainstream linguistic theory represented by Saussure. Saussure's linguistic theory, which was initiated by Saussure with the principle of difference as the core, has been regarded as the starting point of the literary theory by the academic circles at home and abroad. In the "Manuscript of General Linguistics", he distinguishes between event and system, and draws a line between "language events and language systems". The author holds that language can be understood as event from two aspects of progressive degree: (1) although language begins to break the stability of the system, it is only in the degree of "common deviation", and homogeneity is greater than heterogeneity. At best, it only takes the first step of anti-language. (2) There is also the possibility of heterogeneous deviation from the stability of the language system, which produces a completely new and special "absolute infinite change" for the first time (that is, never before)[9], and causes a change in the whole state. From here, we can clearly see Saussure's own dialectical understanding of the relationship between event and language, which accords with the historical fact of event philosophy. That is, event has gradually formed a number of heterogeneous tensions in tit-for-tat opposition to mainstream linguistic theory in the development of event. An in-depth examination shows the level between these tensions.

\subsection{Begin to Question Differences, But Do Not Deny that Differences Are Still Part of the Meaning}

This is mainly the view put forward by Paul Ricoeur. On the one hand, influenced by the French theory of the same period, he kept a vigilant distance from the unity of Saussure's linguistic thoughts, and thought that the resulting structural system had the limitation of inundating events, and estimated the transcendence of events to the structure. On the other hand, it does not completely negate Saussure's linguistic thought based on the principle of difference, but believes that difference is still a part of meaning. Ricoeur pays attention to language and believes that language acts as a trader between structure and event. He not only acknowledges that it is related to structure and exists as a semantic potential, but also believes that it is related to behavior and event and actively realizes semantics. Therefore, for Ricoeur, unity, fundamentality, systematicness and closeness should indeed be broken, just as he tried to re-recognize "cogito". But this fundamental breakthrough does not mean that it is necessary to enter "an organization without object or subject" [10]. On the contrary, the order and distinction between beginning and end, internal and external still exist in Ricoeur's hermeneutic theory and are persisted by him.

\subsection{Object to Differences and Think that Non-misconstructed Differences Are Meaningless}

Similarly opposed to differences, some other literary theorists after Ricoeur did not think that differences were part of meaning, but directly declared the meaningless and truly meaningful differences of Saussure's theory of difference from a new point of view. This was pioneered by Jean-Francois Lyotard earlier. Although he does not deny that events are different, he believes that "when you use a noun to create a verb, there is an event: the rule system of language not only cannot explain this new usage, but also opposes it. It resists this use" [11] because "Saussure's description of symbolic meaning rather than value has an ambiguous attachment". Ignoring the "complexity" under the destruction of "violence" and directly benefiting from Saussure's structuralism, it is also accompanied by Hegel's dialectical thinking, which "depends on the opposition expounded in discourse and image and the suppression of the fundamental meaning of difference" [12], and fails to discover the "fundamental meaning of difference" [12]. And the difference is solidified in the idea intentionally or unintentionally. In contrast, Lyotard argues that events should be "found in the disorder of cognition" and accompanied by "some kind of rule disorder" [13]. Therefore, he proposes to break the concept of narrative organism of linear development. This was later inherited by Derrida theorists. They pay attention to the deconstruction operation of possibility and tend to think that God is a different result and product, and although there are differences, the difference does not arouse doubt in terms of obtaining certainty. Focusing on the deconstruction operation of impossibility, we advocate that "we should not regard difference as God" [14], that is, we should not regard difference as something that can be constructed and material. the essence of doing so is to give the event a strong logic added from the outside-either salvation or resurrection, but as something that is not simply happening literally, but is happening all the time, that is, "the event is a singularity" [14]. It is a difference that makes a difference, a fundamental change or deformation of a situation.

\subsection{Oppose the Difference and Replace the Difference with Silence}

Similarly opposing differences, the third kind of heterogeneity tension against language neither recognizes that it is part of meaning, nor that it is meaningless, but replaces language with silence and distinction with silence. The representative on this point is Jacques Rancière. In the context of questions similar to Saussure, Rancière also reminds people to pay attention to the situation of "the same name has a different meaning" in history, that is, the same name refers to different things with different meanings. In this case, while a word corresponds to one meaning, it always cancels another meaning, and the subject uses words to determine the meaning, but makes himself the victim in turn. This situation, which was normal in Saussure's eyes, was abnormal in Rancière's view. The latter attempts to establish a kind of knowledge poetics to explore how knowledge (the relationship between name and meaning) should be read and written, so that events are no longer regarded as an explanatory framework or rhetorical product inserted into the existing scope of discourse, but are 
associated with "non-lieu" [15]. Thinking about event in the silence of words constitutes Rancière's new strategy.

He found that history is full of the normality of synonyms, which is caused by language: the non-identity of symbols and things, of course, will lead to synonyms. This is supposed to constitute an event because it leads to a kind of "nothing" that can never be caught by any presupposition. However, the theory of language uses the principle of difference to crack this kind of non-identity, and it is believed that through the difference between symbols, it can turn "nothing" into "being", so that the non-existent side of the event always exists, as if the problem can be solved once and for all. In fact, it regards the "nothing" as the nature of the event as a "void" that can always be filled and replaced without accident, safety and stability in the differential distinction. In this line of thinking, the real "nothing", which no longer exists, is optimistically ignored. Our misunderstanding of the writing of history lies in the excessive trust in the power of language, so as to cover up the gap of "nothing" hidden behind the superficial distinction.

\subsection{Replace the Difference with Technical Event and Spectral Property to Get out of the Delay of Language}

From pointing out that the difference is meaningless, to trying to replace the difference with other factors, it is not only practiced by Rancière, but also further considered and promoted by the more recent fourth kind of heterogeneous tension in the same way of thinking. Bernard Stiegler, a French thinker who died in 2020 and wrote a five-volume book "Technology and Time", directly quoted the relevant arguments at the beginning of this article, and found a new factor that replaces differences and is no longer confined to linguistic thinking. this is media technology. He argues that the reason why the construction of past history can become an event lies not in how the delay of the narrative is coordinated with its scene as much as possible, but in that the intervention of media technology directly serves as the reason and motivation to ensure the identity of the event and the narrative of the event (Stigler calls it "input"). Why, in his view, can media technology overcome the gap between event and narration that Ricoeur sees as difficult to bridge?

Because today, with the great progress in the transmission speed of analog and digital media, there is no longer a striking difference between broadcasting and live broadcasting. Spectral property, that is, unexpected and divine factors that are not regulated by any stable system, including symbolic differences, is another visual expression of events. Close to Stigler, Louis Armand also agrees that modern media technology directly acts as language and speaks events, and believes that this critical structure is a "symbolic probability machine" that is different from Saussure [16], but still belongs to language, which not only ensures the unique occurrence of events in structure, but also confirms that it lies in its own logic of development. In the final analysis, it is necessary to solve the problem that the mainstream linguistic theory is also focused all the time: "say" and "in" are kept as one of the two, and are realized as an inseparable one.

\section{Conclusions}

From the above analysis, we can see that the basic meaning of philosophy of event is "dynamic change and transformation", but it does not simply repeat the premise that human way of thinking gradually evolved from static to dynamic after entering the 20th century, but on this basis, emphasize the difference and heterogeneity of dynamic change and transformation, and attach importance to the intervention and impact of singular forces. This emphasis not only actively changes the static metaphysical model of human thought, but also changes the dynamic metaphysical model which seems to have tended to be dynamic, but still unwittingly falls into another kind of homogenization pattern The problem consciousness of philosophy of event is mainly reflected in the transcendence of mainstream linguistic theory.

As a result, the significance of studying philosophy of event is finally highlighted. Since the philosophy of event in Europe is mainly contrary to the mainstream linguistic theory represented by Saussure, when the British and American scholars in the same period began to pay attention to "after theory", because the "theory" is based on the mainstream linguistic theory, it is a natural choice for the post theory, which is mainly popular in the Anglo-American academic circles, to introduce philosophy of event as a driving force. This will help post theoretical research to get out of the dominant Anglo-American paradigm and gain the motivation of Europe. As two frontier topics in recent humanities, philosophy of event and post theory have obtained a deep connection based on theoretical logic. This connection will continue to reflect the importance of pushing through the old and bringing forth the new in the future.

\section{References}

[1] Raman Seldon, Peter Widson, Peter Brooke. An Introduction to Contemporary Literary Theory. translated by Liu Xiangyu. Beijing: Peking University Press, 2006: 326-340.

[2] Slavoj Žižek. Event. translated by Wang Shi. Shanghai: Shanghai Literature and Art Publishing House, 2016: 90-91.

[3] Thomas Kuhn. The Structure of the Scientific Revolution. translated by Jin Wulun and $\mathrm{Hu}$ Xinhe. Beijing: Peking University Press, 2003: 111.

[4] Timothy Clark. The Poetics of Singularity. Edinburgh: Edinburgh University Press, 2005: 20.

[5] Terry Eagleton. After Theory. translated by Shang Zheng, Beijing: Commercial Press, 2009: 71.

[6] Liu Yang. History of Event Thoughts. Shanghai: East China normal University Press, 2021: 1-500.

[7] Michel Serres. Branches: A Philosophy of Time, Event and Advent. Bloomsbury Academic, 2020: 105.

[8] François Raffou. Thinking the event. Indiana University Press, 2020: 6 
[9] Ferdinand de Saussure. Manuscripts of General Linguistics. Translated by Yu Xiu-English. Beijing: commercial Press, 2020: 261.

[10] John Michel. Ricoeur and the Post-Structuralists. London: Rowman, 2015: 79.

[11] Jean-Francois Lyotard. Discourse, Graphics. translated by Xie Jing. Shanghai: People's Publishing House, 2012: 170.

[12] Geoffrey Bennington. Lyotard: Writing the Event. New York: Manchester University Press, 1988: 68-69.
[13] Jean-Francois Lyotard. Discourse, Graphics. translated by Xie Jing. Shanghai: People's Publishing House, 2012: 157-158.

[14] Clayton Crockett. Derrida After the End of Writing: Political Theology and New Materialism. Fordham University Press, 2018: 97.

[15] Jacques Rancière. The Name of History: on the Poetics of Knowledge. Translated by Wei Deji and Yang Chunxian. Shanghai: East China normal University Press, 2017: 37.

[16] Louis Armand. Event States: Discourse, Time, Mediality. Prague: Litteraria Pragensia, 2007: 286. 